\title{
Abismo y modernidad: ensayo sobre Nietzsche y el Romanticismo
}

\author{
REBECA MALDONADO \\ El Colegio de México-UNAM-FFyL
}

Las observaciones y los cálculos de los astrónomos nos han enseñado muchas cosas admirables, pero lo más importante es, sin duda, el habernos revelado el abismo de nuestra ignorancia. Sin tales conocimientos, la razón humana nunca hubiese pensado que ese abismo fuese tan grande.

I. Kant, Crítica de la razón pura. ${ }^{1}$

Una vez que el mundo suprasensible se reveló inaccesible a la razón, el pensamiento inaugura un nuevo ámbito de su despliegue y convertirá al abismo en toda una intuición estética y filosófica que permitirá dar forma al colapso de lo suprasensible. La quiebra de lo suprasensible -tematizado bajo el término huida o noche de los dioses- va confluir en el romanticismo en una crítica a aquello que logró sobrevivir de las aspiraciones de la razón: el dominio de la razón físico-técnica ${ }^{2}$. La razón después de la Ilustración logra nuevamente reorganizarse como dominio incondicionado de los entes, abandonando, sólo así, su aspiración a lo incondicionado suprasensible ${ }^{3}$. El dominio de la razón físico-técnica se transformará en adelante en el eje de las existencias y se revelará desde entonces como marca de nuestra actualidad. Éste destino se extiende inamovible desde hace dos siglos, constituyéndose en un presente perpetuo; mientras tanto una línea de pensamiento trató de constituir su antídoto: ante esta apariencia de progreso, iluminación y poder de la razón físico-técnica desplegado en el mundo, para el Romanticismo nos encontramos en medio de la más negra noche, las tinieblas nos cubren, porque también, paradójicamente, esa razón pretendió ocultar y sepultar el abismo que nos constituye y, con él, las

${ }^{1}$ Kant, I., Crítica de la razón pura, Madrid: Alfaguara, 1978, p. 490.

${ }^{2}$ Frank, M., El dios venidero. Ensayos de nueva mitología, Madrid: Del Serbal, 1994.

${ }^{3}$ Asunto que se puede colegir tras la atenta lectura de Heidegger, M., «La superación de la metafísica», en Artículos y conferencias, Madrid: Del Serbal, 1994. 
fuerzas creadoras, intuitivas y poéticas que guarda en su seno. Desde entonces, el abismo se transformará en el lugar que habrá de sondear el pensamiento poético y filosófico. Desde Schiller, Novalis, Hölderlin hasta Nietzsche el abismo será una indicación, e incluso, una vía en medio de la modernidad.

\section{HACIA El MAR SIN ORILLAS DE LAS IDEAS, Kant}

La vía del abismo nunca se hubiera manifestado si no hubiera acontecido en el ámbito del pensamiento un hecho de repercusiones interminables como fue la Crítica de la razón pura. El verdadero fundador de la réplica a la modernidad desde la perspectiva del abismo o falta de fundamento fue sin lugar a dudas $\mathrm{Kant}^{4}$. Este filósofo fue el primero que se atrevió al abismo insondable de nuestra ignorancia, él fue el primero que lo formuló como abismo, mar insondable e, incluso, mar sin orillas. Al concebir el entendimiento ligado a la sensibilidad, ámbito seguro del conocimiento y de la verdad, instará al ser humano a permanecer en las continuas costas de la experiencia, pero la metafísica será el abandono de dichas costas: el desdibujamiento completo de cualquier orilla. Por eso dirá Kant de la metafísica: «se trata de un mar sin riberas en donde el progreso no deja huella alguna, y cuyo horizonte carece de término visible que permita percibir cuán cerca se esté de él» ${ }^{5}$. En otro lugar señala Kant, «me he atrevido, por consiguiente, a lanzarme mejor a ese mar sin riberas de las ideas ${ }^{6}$. Al abismarse en el mar de las ideas, Kant desmiente el optimismo de la razón con respecto a la capacidad ilimitada de conocimiento y a la posibilidad de proponer un fundamento. En su Crítica de la razón pura muestra que dado que las ideas de la razón carecen de objeto que les corresponda, la razón no puede alcanzar la totalidad incondicionada, no puede dar con la causa última de los fenómenos y no puede realizar salto alguno de lo condicionado a lo incondicionado. La tentativa de la razón teórica de alcanzar lo ilimitadosuprasensible está destinada al fracaso y, por lo tanto, sus esfuerzos han de confinarse al campo de los objetos dados a la intuición sensible. De este modo, en la cúspide de la Ilustración encontramos la primera réplica al optimismo de la razón con respecto a su capacidad ilimitada de conocimiento. Las cosas en general, las cosas que no se ofrecen a una intuición sensible, constituyen para la filosofía crítica un ámbito especulativamente vedado. Dice Kant a punto de concluir la Analítica trascendental: «No sólo hemos recorrido el territorio del entendimiento puro y examinado cuidadosamente cada parte del mismo, sino que, además, hemos comprobado su extensión y señalado la posición de cada

${ }^{4}$ Maldonado, Rebeca, La razón estremecida. Ensayo sobre Kant, México: Pleroma Ediciones-FFyL-UNAM (en prensa).

${ }^{5}$ Kant, I., Los progresos de la metafisica desde Leibniz a Woolf, Madrid: Tecnos, 1987, p. 7.

${ }^{6} \mathrm{Cf}$. nota a pie de página del traductor, op. cit., p. 15. 
cosa. Ese territorio es una isla que ha sido encerrada por la naturaleza entre límites invariables [unveränderliche Grenzen]. Es el territorio de la verdad [Land der Wahrheit, un nombre atractivo] y está rodeado por un océano ancho y borrascoso [umgeben von einemweiten und stürmischen Ozeane], verdadera patria de la ilusión [Sitze des Scheins], donde algunas nieblas y algunos hielos que se deshacen [...] producen prontamente la apariencia de nuevas tierras y engañan una y otra vez con vanas esperanzas al navegante ansioso de descubrimientos, llevándolo a aventuras que nunca es capaz de abandonar, pero que tampoco puede concluir jamás ${ }^{7} \gg$.

Esta metáfora espacial muestra la tarea filosófica propiamente dicha, ésta consiste no en permanecer en las tranquilas costas de nuestra experiencia, sino en lanzarse al mar sin orillas de las ideas o de lo suprasensible, tal y como Kant lo ha hecho en la Dialéctica trascendental. Pues, «no obstante, no nos parece suficiente limitarnos a exponer lo que es verdad, sino que quisiéramos examinar también lo que deseamos saber ${ }^{8}$. Y, por lo tanto, introducirse en ese mar ancho y borrascoso es introducirse en un espacio sin horizonte ni término visible. Es aquí donde se plantea una descripción romántica de la razón humana, no sólo por la referencia al mar ancho y borrascoso, sino porque se muestra el modo esencial del espíritu romántico que en la historia del pensamiento está a punto de mostrarse franca y abiertamente gracias a Kant. Efectivamente, Kant desocultará en el ser del hombre un impulso que lo lleva a no contentarse con los horizontes y límites precisos, con las costas seguras de nuestro limitado mundo práctico; hará emerger en la razón, una tendencia del pensamiento que buscará deslizarse hacia lo ilimitado, no preciso, no confinado que va mucho más allá de las aspiraciones de la razón a lo incondicionado-suprasensible. Comenzará la tendencia del pensamiento a abrir el abismo ahí donde se pretenda haber alcanzado una isla, un horizonte definido o un territorio preciso.

Este saber tendrá que esperar a que pase la enérgica reacción filosófica de Fichte y Hegel que trató de enraizar de nuevo en la filosofía el absoluto o lo incondicionado hasta la aparición de las filosofías de Schopenhauer y Nietzsche. Ambos formarán parte de un movimiento de pensamiento que justamente Kant desocultó. Escribe Nietzsche en El nacimiento de la tragedia «la valentía y sabiduría enormes de Kant y Schopenhauer consiguieron la victoria más difícil, la victoria sobre el optimismo que se esconde sobre la esencia de la lógica, y que es a su vez el sustrato de nuestra cultura». ${ }^{9} \mathrm{Y}$ añade: «Si luego recordamos como Kant y Schopenhauer dieron al espíritu de la filosofía alemana, [...], la posibilidad de aniquilar el satisfecho placer de existir del socratismo científico,

${ }^{7}$ I. Kant, Crítica de la razón pura, p. 259 (A236).

${ }^{8}$ Ibid., p. 260 (A237). «So scheint es uns doch nicht genug, sich bloss dasjenige vortragen zu lassen, was wahr ist, sondern, was man zu wissen begehrt» ibid., p. 323 (A237).

${ }^{9}$ NT, Madrid: Alianza, 1989, p. 148. 
al demostrar los límites de éste, cómo con esta demostración se inicio un modo infinitamente más profundo y serio de considerar los problemas éticos y el arte, modo que podemos calificar realmente de sabiduría dionisíaca ${ }^{10}$.

Efectivamente, Kant es el iniciador de la sabiduría dionisíaca en el momento mismo que reconoce que la raíz metafísica del ser humano emerge desde el abismo Para este filósofo, la razón busca concebir un fundamento, porque de lo contrario estaría frente a la universal contingencia de todas las cosas. Si la razón humana quiere un entendimiento supremo y de infinita realidad, dicho anhelo nace justamente del miedo al abismo. Dice Kant: «Este suelo se hunde cuando no descansa en la roca inamovible de lo absolutamente necesario. Y esta [misma] roca flota, a su vez, en el aire si hay aún espacio vacío fuera y debajo de ella, si no lo llena todo por sí sola de modo que no deje margen al por qué, es decir, si no es infinita en su realidad» ${ }^{11}$. Más tarde en la Crítica del juicio Kant ahondará en la condición ilimitada e indeterminada de la subjetividad ${ }^{12}$. Así, cuando habla de la experiencia de lo sublime, nos dirá que la visión del mar en agitada tormenta o de la cadena de desordenadas montañas, son experiencias de infinitud que muestran lo ilimitado de nuestra facultad suprasensible. Es decir, la propia descripción kantiana de la razón con la metáfora de «océano ancho y borrascoso» (einem weiten und stürmischen Ozeane) mienta lo ilimitado en nosotros. Ésta es la esencia de la experiencia de lo sublime, entrever desde lo particular y lo finito, lo indeterminado o lo carente de límites en nosotros. A través de una representación particular es posible ver más allá en lo infinito, produciéndose un verdadero ensanchamiento del espíritu ${ }^{13}$. Lo sublime es la experiencia de dicho ensanchamiento. Se apunta, se tiende hacia lo suprasensible, pero no se posee, no se tiene dominio de él, pues está fuera del dominio de las facultades cognoscitivas. La experiencia de lo sublime se origina en una facultad que supera toda medida de los sentidos, en una facultad que es transgresora de todo límite y de toda forma, y que podemos pensarla como facultad abismal. Pues esa facultad, que en la superación de los límites nos deja absolutamente abiertos, constituye la vía privilegiada de acceso a nuestra ilimitación originaria.

${ }^{10}$ Ibid., p. 150. Ahora bien, dicha sabiduría es aquella que «sin las seducciones de las ciencias, se vuelve con mirada quieta hacia la imagen total del mundo e intenta aprehender en ella, con un sentimiento simpático de amor, el sufrimiento eterno como sufrimiento propio»» ibid., p. 148.

${ }^{11}$ I. Kant, La crítica de la razón pura, p. 495 (A584). En el original el subrayado se lee: «Dieser Boden aber sinkt, wenn er nicht auf dem unbeweglichen Felsen des Absolutnotwendigen ruhet. Dieser selber aber schwebt ohne Stütze, wenn noch ausser und unter ihm leerer Raum ist» ibid., p. 621 (A584).

${ }^{12}$ I. Kant, Crítica del Juicio, tr. M. García Morente, Madrid: Espasa Calpe, 1997, pp. 100-101.

${ }^{13}$ «Lo propiamente sublime no puede estar encerrado en forma sensible alguna, sino que se refiere tan sólo a ideas de la razón, que aunque ninguna exposición adecuada de ellas sea posible, son puestas en movimiento y traídas al espíritu justamente por esa inadecuación que se deja exponer sensiblemente» ibid., p. 185. 
La experiencia de lo sublime es experiencia de no fundamento, mediante ella descubrimos «una insondable profundidad de esa facultad suprasensible que se extiende hasta donde ya no alcanza la vista» ${ }^{14}$.

El romanticismo formará parte de la victoria sobre la existencia fundada en la fe en la ciencia; al ahondar en el ilimitado y tormentoso mar del ser del hombre comprendió que éste está habitado mucho antes que por ideas, por fuerzas oscuras, deseos y sueños o como piensa Hölderlin «por la extraña nostalgia del abismo», ésa por la cual «lo indefinido atrae siempre» ${ }^{15}$.

2. Abismo, Misterio y problema o El NUEVo ESPACIO DE LA VERDAD o El ABISMO

En el abismo es donde habita la verdad. F. Schiller ${ }^{16}$

El Romanticismo no se contentará con lo finito, condicionado y sensible, ahondará en la indeterminación de lo suprasensible. «Huid de los límites de la sensibilidad». ${ }^{17}$ Es decir, el Romanticismo reinterpretará el campo de lo suprasensible como lo ilimitado, inaccesible, indefinido, imposible de acceder por la razón teórica y por las leyes que gobiernan el mundo sensible, transformándolo poco a poco en las fuerzas oscuras que modelan nuestro destino, en el ámbito de la noche y el sueño, en los aspectos de la vida que escapan a la voluntad humana y en general a nuestra conciencia. «Hablamos de nuestro corazón, de nuestros planes, como si fueran nuestros, cuando es una potencia extraña la que nos abate y nos echa a la tumba a su gusto, y de la que no sabemos ni de dónde viene ni adónde va. Queremos crecer y extender hacia arriba nuestros troncos y ramas, pero son el suelo y la tormenta las que nos conducen hacia otra dirección, y cuando el rayo cae en tu copa y te hiende de arriba abajo hasta la raíz, ipobre árbol!, ¿qué puedes hacer?» ${ }^{18}$.

En el Romanticismo emergerá la idea de la existencia de potencias y fuerzas involuntarias que constantemente hacen que la vida se manifieste como misterio o como lo imposible de esclarecer. "Oh eterno misterio, lo que somos / y buscamos no podemos encontrar; / lo que encontramos, no somos!» ${ }^{19}$. Asimismo el pensamiento romántico echará por tierra la idea

${ }^{14}$ Ibid., p. 217

15 «Das wunderbare Sehnen dem Abgrund zu; / Das Ungebundne reizet...» Hölderlin, F., Poesía completa, ed. F. Gorbea, Barcelona: Ediciones 29, 1995, p. 249.

${ }^{16}$ «Um im Abgrund wohnt die Wahrheit» Schiller, F., Poemas filosóficos, ed. D. Innerarity, Madrid: Hiperión, 1994, p. 137.

${ }^{17}$ Ibid., pp. 68-69.

${ }^{18}$ Hölderlin, F., Hiperión o el eremita en Grecia, Madrid: Ediciones Hiperión, 1998, p. 63.

${ }^{19}$ Hölderlin, F., Empédocles, Madrid: Hiperión, 1997, p. 51. 
ilustrada de la historia que considera que nuestra acción sobre el mundo nos lleva a iluminaciones progresivas, que la emancipación del hombre radica en el valor de servirse de su propia razón y que la historia es expresión de la naturaleza racional del hombre. Por el contrario, el pensamiento ahondará en los aspectos oscuros del ser humano. "¿Qué es lo que hace que el hombre desee con tanta fuerza?", me preguntaba a menudo; “¿qué hace en su pecho la infinitud? ¿La infinitud? ¿Y dónde está? ¿Quién la ha encontrado?” El hombre quiere más de lo que puede. Esto al menos es verdad. [...] Ello proporciona el dulce y exaltante sentimiento de una fuerza que no se expande como desearía, que es precisamente lo que hace nacer los hermosos sueños de inmortalidad y todos los amables y colosales fantasmas que fascinan mil veces al hombre, ello crea en el hombre su Eliseo y sus dioses, precisamente porque la línea de su vida no es recta, porque no vuela como una flecha y porque una fuerza extraña se cruza en el camino del fugitivo. "Las olas del corazón no estallarían en tan bellas espumas no se convertirían en espíritu si no chocaran contra el destino, esa vieja roca muda" $\gg{ }^{20}$

Incluso nuestras ideas de infinitud más preciadas como la de la inmortalidad, emergerán de fuerzas potentes, desconocidas, que conducen sin embargo a lo irregular, a un ciego y mudo destino. Desde la esfera de lo ideal y de lo superior que era lo suprasensible, éste se ve jalonado por el Romanticismo hacia lo oscuro abriéndose, en definitiva, el verdadero abismo en el hombre. «No hay ancla que toque fondo», dice también Schiller ${ }^{21}$. Pero además el Romanticismo transforma el abismo y la profundidad en el ámbito de la verdad: «Tienes que descender a las profundidades / para que la esencia se te revele $»^{22}$. Pareciera ser que la verdadera experiencia a la que invoca el Romanticismo es a la experiencia de nuestro misterio, de nuestro lado nocturno y de nuestro ser abismal. Esto es, para el Romanticismo el ser humano entra en el territorio de la verdad cuando logra calar en el abismo, cuando logra la experiencia de su carácter mistérico e insondable. «¿Hay alguno / entre nosotros que no esconda en su pecho / algún presentimiento, algún problema? $\gg^{23}$. Sin embargo, para lograr la experiencia del abismo se hace necesario traspasar toda particularidad, toda determinación sensible y unidimensional, entendiendo por tal, lo que el pensamiento posterior tematizará como modernidad, esto es, el modo de ser que atraviesa la cultura guiado por criterios exclusivamente pragmáticos, cientificistas y utilitaristas. En el esbozo para escribir Hölderlin su Empédocles leemos «Empédocles, inducido por su sensibilidad y su filosofía a odiar la cultura, a despreciar toda ocupación muy definida, todo interés dirigido a objetos diferenciados, enemigo mortal de toda existencia unilateral y, por

\footnotetext{
${ }^{20}$ Hölderlin, F., Hiperión, pp. 65-66.

${ }^{21}$ «Und kein Anker findet Grund» Schiller, F., Poemas filosóficos, pp. 68-69.

22 «in die Tiefe musst du steigen / Soll sich dir das Wesen zeigen» ibid.

${ }^{23}$ Hölderlin, F., Poesía completa, p. 233.
} 
tanto, insatisfecho, inestable, doliente, incluso en condiciones realmente bellas, simplemente porque son condiciones particulares y sólo le satisfacen sentidas en armonía con todo lo que vive, simplemente porque él no puede con corazón omnipresente, amarlas y habitarlas, férvido como un dios, libre y extenso como un dios, simplemente porque, tan pronto como su corazón y su pensamiento abrazan lo existente, está ligado a la ley de la sucesión...» ${ }^{24}$.

El Romanticismo propone como método el descenso al abismo y para lograrlo ha de traspasar la modernidad y sacar a la luz el enigma y el misterio que somos. La modernidad se revela como el ocultamiento extremo del abismo en el ser del hombre. Pues, mientras que la modernidad intenta construir coordenadas precisas al devenir, el pensamiento consciente del abismo insiste en el carácter misterioso, ciego e insondable del alma. Mientras que en la modernidad el alma está caída en el campo de lo sensible y mide desde ahí sus limitaciones y sus alcances creando una y otra vez expectativas ilusorias de perfeccionamiento; el pensamiento del abismo insiste en las fuerzas, en el destino y en la oscuridad; mientras que la modernidad vuelve a pensar que el territorio seguro es el dispuesto por el número, el Romanticismo piensa que más ancha es la noche y el sueño. El Hiperión, Empédocles y Cantos a la noche constituyen en su conjunto un documento del primer enfrentamiento de la conciencia con la modernidad que lleva a los románticos o bien a buscar el abismo, el sueño o finalmente Grecia y, dar en los tres casos con el misterio del ser humano como verdadera fuente de la belleza e incluso de los dioses. Por primera vez en la historia del pensamiento ocurre una revisión del mundo como una determinada constelación de la ordenación del mundo sensible. Pero ¿cuál es la esencia del mundo sensible constituido culturalmente? La visión científico-técnica se impone sobre el mundo, los dioses huyen y se refugian en el sueño y en la noche. Así dice Novalis en Himnos a la noche: «Los dioses desaparecieron con su séquito -Quedó la naturaleza inerte y solitaria. El número árido y la estricta medida la ataron con férreas cadenas. Igual que en polvo y viento se deshizo en oscuras palabras la inmensurable exuberancia de la vida. Huyó la fe con sus conjuros, huyó su divina compañera, la imaginación que todo lo transforma y todo lo hermana...Acompañada de todas sus fuerzas el alma del mundo fue a asilarse en el más profundo santuario, en el alto recinto del corazón humano donde se dominaría hasta que despuntara la esplendorosa aurora universal. La luz dejó de ser morada de los dioses y signo celeste -los dioses se cubrieron con el velo de la noche. Fue la noche el inmenso seno donde se engendran las revelaciones -a él regresaron los dioses- en él se durmieron para, en nuevas espléndidas formas, reaparecer un día ante el mundo transformado» ${ }^{25}$.

${ }^{24}$ Hölderlin, F., Empédocles, p. 25.

${ }^{25}$ Novalis, Himnos a la noche. Cánticos espirituales, ed. A. Ferrari, Valencia: Pre-textos, 1995, p. 53. 
En la nueva configuración del mundo sensible la cual critica el Romanticismo, el ser humano está arrojado en la intramundanidad de los entes, en la modernidad todo es susceptible de compra-venta y, por lo mismo, en ella está exiliada la belleza: «si realmente les falta también el espíritu de todo lo bello, será porque no se puede ni exportar ni comprar ${ }^{26}$. Además de la ausencia de la belleza, con el advenimiento, de la constelación ciencia-dominio del ente el ser humano al ser expulsado de la naturaleza es concebido como un ser sin patria. Hölderlin después de afirmar «la ciencia lo ha estropeado todo» agrega: «En vuestras escuelas es donde me volví tan razonable, donde aprendí a diferenciarme de manera fundamental de lo que me rodea; ahora estoy aislado entre la hermosura del mundo, he sido así expulsado del jardín de la naturaleza, donde crecía y florecía, y me agosto al sol del mediodía $»^{27}$. El abismo (el sueño, la noche, el pasado) será pensado en el Romanticismo como el refugio ante la irrupción de la visión científico- utilitaria del mundo. «Quisiera sacudir de mí lo que me dio mi siglo e irrumpir en el reino más libre de las sombras» ${ }^{28}$. Dice Novalis en Cánticos espirituales: «El que hunde su mirada en el pasado / Imagen del abismo / Atraído a sus simas por la dulce / tristeza que lo asedia;- // Como si allá en el fondo se hacinaran / Tesoros prodigiosos, / Cerrados a la mano que él alarga Jadeante y tembloroso ${ }^{29}$. El Romanticismo es la defensa del misterio del ser humano y de su poder creador, bajo esta premisa el Romanticismo constituirá al abismo en refugio y sustento en la época de la modernidad. Si el ser humano ha de protegerse y encontrar un lugar mientras pasa la modernidad es en el abismo, ahí se hunden los nacidos divinos. En la elegía «El archipiélago» de Hölderlin leemos:

...resuena a menudo joh dios del mar!

En mi alma con tus olas, para que sobre las aguas prevalezca

sin temor el espíritu, como el nadador, se ejercite en la fresca dicha de los fuertes, y comprenda el lenguaje de los dioses,

el cambio y el acontecer; y si el impetuoso tiempo

conmueve demasiado violentamente mi cabeza,

y el desvarío y la miseria de los hombres estremecen

mi alma mortal, ¡déjame recordar el silencio en tus profundidades! ${ }^{30}$

${ }^{26}$ Hölderlin, F., Hiperión, p. 121.

${ }^{27}$ Ibid., p. 26.

${ }^{28}$ Ibid., p. 38.

${ }^{29}$ «Wer in das Bild vergrangner Zeiten / Wie tief in einen Abgrund sieht / In welchen ihn von allen Seiten; /- Ein sübes Weh hinunter zieht; // Es ist, als lägen Wunderschätze / Da unten für uhn aufgehäuft, / Nach deren SchloB in wilder Hetze / Mit atemloser Brust er greift Novalis, Himnos a la noche, p. 94-95.

${ }^{30}$ «... aus deinen Wogen, o Meergott! / Töne mir in die Seele noch oft, dass über den Wassern / Furchlos rege der Geist, dem Schwimmer gleich, in der Starken / Frischem Glücke sich üb, und die Gotterschprache, das Wechseln / Und das Werden versteh, und wenn die reissende Zeit mir / Zu gewaltig das Haupt ergreift und die Not und das Irrsal / Unter Sterblichen mir mein sterblich Leben erschüttert, / Lass der Stille mich dann in deine Tiefe gedenken» Hölderlin, F., Las grandes elegías, ed J. Talens, Madrid: Hiperión, 1994, pp.43-45. 
La posición radical de la transformación del abismo en refugio y en salida de la modernidad durante el Romanticismo la constituye el Empédocles de Hölderlin. En dicha obra, Empédocles después de acusar a su tiempo «huérfano de héroes» $\mathrm{y}$ «sin dioses» incluso de comerciar con lo sagrado, de corromper los corazones, y de transformar a los seres humanos en rostros falsos y fríos, se precipita en el abismo. Exclama Empédocles «y en sus profundidades, desvanecíanse mágicamente mis enigmas $»^{31}$.

La influencia del Empédocles de Hölderlin en Nietzsche es innegable, incluso la tarea zaratustriana de descender al abismo y de ingresar en las profundidades, parece inspirada por fragmentos de la obra de Hölderlin. Leemos en el Empédocles:

- ¿Tan caro ha de pagar el haber confiado

a los mortales lo mejor de su alma plena?

-Que lo haga, pero no por eso Némesis no llegará.

Que pronuncie grandes palabras,

que envilezca la vida secreta y casta

y saque a la luz del día el oro de las profundidades ${ }^{32}$.

La cercanía del pasaje anterior con el Zaratustra es innegable, ahí leemos: «Pero el oro y la risa - los toma desde el corazón de la tierra: pues para que lo sepas, - el corazón de la tierra es de oro». ${ }^{33}$ Efectivamente, los románticos se lanzan al abismo, se precipitan en él, concibieron que del Abismo «asciende el poderoso anhelo», que en él habitan las potencias puras, pero sólo es a Nietzsche a quien le está reservado extraer de la Tierra su sentido, y realizar cabalmente el movimiento de descenso y ascenso ${ }^{34}$. Nietzsche en el prólogo a La gaya ciencia escrito en 1886, muestra en qué sentido va más allá de lo encontrado por el Romanticismo en el abismo. Pero para comprenderlo, es indispensable entender qué entiende él mismo por Romanticismo: «Este trozo de desierto, de agotamiento, de incredulidad, de congelamiento en medio de la juventud, esta ancianidad insertada en un lugar inapropiado; esta tiranía del dolor superada aún por la tiranía del orgullo, que rechazaba las conclusiones del dolor $-\mathrm{y}$ las conclusiones son consuelos-; este radical quedarse solo como defensa extrema contra un desprecio por los hombres, que se había vuelto clarividente; esta restricción fundamental a lo amargo, áspero y doloroso que posee el conocimiento, tal como lo prescribía la náusea que paulatinamente había crecido a partir de una dieta espiritual y condescendencia imprudentes - a eso se le llama romanticismo» ${ }^{35}$.

${ }^{31}$ Hölderlin, F., Empédocles, p. 71.

${ }^{32}$ Ibid., p. 231.

${ }^{33}$ Za, Madrid: Alianza, 1985, p. 195.

${ }^{34}$ «Llena de callada fuerza, la gran naturaleza / abraza al que vive presagiando; / para que invoque a su espíritu, lleva / en el pecho pena y esperanza al hombre, / de su más honda entraña asciende el poderoso anhelo. / Y es capaz de muchas cosas y espléndido / es su decir, transforma el mundo/y entre las manos» Hölderlin, F., Empédocles, p. 259.

${ }^{35}$ GC, Caracas: Monte Ávila, 1985, p. 2. 
Se trata de la descripción y definición nietzscheana del Romanticismo, mientras que el Romanticismo se detiene en el dolor, en el desprecio a los hombres y en lo amargo, áspero y doloroso del conocimiento, Nietzsche sin dejar de reconocer que ambos son condición fundamental de la filosofía, irá más allá de todo dolor y de todo desprecio; al descender a la profundidad en todas sus versiones tanto en El nacimiento de la tragedia, como en Humano, demasiado humano, Aurora y La gaya ciencia y en Así habló Zaratustra encuentra distintas formas de afirmación y justificación de la existencia. «Al hombre le ocurre lo mismo que al árbol. / Cuanto más quiere elevarse hacia la altura y hacia la luz, tanto más fuertemente tienden sus raíces hacia la tierra, hacia abajo, hacia lo oscuro, lo profundo, - hacia el mal»» ${ }^{36}$.

\title{
3. ITINERARIOS DE ASCENSO Y DESCENSO EN NIETZSCHE
}

\begin{abstract}
Hombre, he ahí tu paracaídas maravilloso como el vértigo Poeta, he ahí tu paracaídas, maravilloso como el imán del abismo. Mago, he ahí tu paracaídas que una palabra tuya puede convertir en un parasubidas maravilloso como el relámpago que quisiera cegar al creador.
\end{abstract}

Vicente Huidobro, Altazor

En su primer itinerario ${ }^{37}$, Nietzsche descenderá al fondo dionisíaco, también denominado «fondo más íntimo del ser humano», «fondo íntimo del mundo» 0 «fundamento único del mundo» ${ }^{38}$. Penetrar ahí, en aquella parte del fundamento de la existencia y superarla una y otra vez mediante la fuerza apolínea transfiguradora es tarea de la ética, el arte y la cultura. Al tiempo que Dioniso es la mezcla de voluptuosidad y crueldad, la condición del tormento y la lamentación que subyace en el fondo de las cosas, el éxtasis nacido del horror del mundo y de la muerte, constituye el éxtasis de la creación, constituye el instinto de la eternidad de la vida, más aún, es lo que garantiza el movimiento, el devenir y la creación. En El nacimiento de la tragedia, Nietzsche manifiesta el juego creador entre lo dionisiaco y lo apolíneo, en la experiencia trágica. Cuando la vida se pierde, cuando se vive lo más contradictorio, insondable e impenetrable de la existencia, cuando se enfrenta el orden perturbado del mundo, cuando se mira el abismo, tanto más urge la visión apolínea que venga a afirmar la existencia, pero también el deseo de la existencia. En ese momento emerge la lucidez del héroe y, en esa lucidez, la voluntad de vida más desencarnada. Este sentido afirmativo de la vida en la experiencia trágica lo expresa Aquiles, que

${ }^{36}$ Za p.72

${ }^{37}$ Maldonado, Rebeca, Metáforas del Abismo. Itinerarios de ascenso y descenso, México, Ediciones Sin Nombre (en prensa).

${ }^{38}$ NT, Madrid: Alianza, 1992, pp. 57, 44 y 47. 
prefiere servir en la casa del esclavo más pobre a pertenecer al mundo de los muertos. Antígona también desciende a la sepultura, atravesada pese a todo por la voluntad de amar y de engendrar. En la experiencia trágica el deseo de la existencia prevalece. «En el estado apolíneo la voluntad desea con tanto ímpetu esta existencia, el individuo homérico se siente tan identificado con ella, que incluso el lamento es un canto de alabanza ${ }^{39}$. Así, Nietzsche nos propone afirmar la vida por medio del acto apolíneo de simbolización, que es, sin lugar a dudas, la justificación de la vida en su totalidad.

En la veta hermenéutica del pensamiento de Nietzsche que aparece hacia la época de Aurora y Humano, demasiado humano se despoja al mundo de todo prejuicio moral, de toda creencia última, de todo lo considerado como último, se despoja al mundo de una sola visión y perspectiva; para entonces, hacer manifiesto la radical y absoluta inocencia de la existencia. Éste es el descubrimiento que Nietzsche realiza en Humano, demasiado humano: «todo es inocencia». Pensamiento luminoso, por liberador. «Vivir es inventar» ${ }^{40}$. Y cada vez que el hombre se desengancha de una verdad y de otra verdad, parece realizar la experiencia de deshacerse de los agarres que lo mantenían sostenido en la roca firme de la verdad inamovible para descender al abismo interminablemente. Si no hay un sentido en sí del mundo, «hemos reconquistado el valor de errar, de ensayar, de adoptar soluciones provisionales» ${ }^{41}$. En oposición a parámetros y horizontes fijos de valoración, se constituyen en valores el ensayo, el experimento y la provisionalidad. El ser humano vive entregado aunque no lo sepa a una necesaria e inminente creación de sentido, pues precisamente porque la vida humana carece de sentidos absolutos e incondicionados, el ser humano ha de crearlos. Nietzsche con una metáfora marina muestra que el espíritu libre, el espíritu liberado de prejuicios e interpretaciones fijas, precisamente comprobará a cada momento lo ignoto y no descubierto del mar perpetuamente abierto de la vida humana: «Nosotros los argonautas del espíritu.- Todos esos pájaros atrevidos que vuelan hacia espacios lejanos, llegará el momento en que no podrán ir más lejos y tendrán que posarse en un bosque o en un pelado arrecife, considerándose felices de hallar ese miserable asilo. ¿Pero hemos de deducir de ahí que no queda delante de ellos un espacio libre y sin fin y que han volado todo lo lejos que se puede volar? [...] Este pensamiento, esta fe que nos anima, toma vuelo, rivaliza con aquellos grandes pensadores que acabaron por detenerse, vuela cada vez más lejos y más alto, se eleva derechamente por los aires encima de la impotencia de las cabezas y desde el azul ve en las lejanías del espacio [...] que todo es mar, nada más que mar, mar y mar. ¿Dónde queremos

\footnotetext{
${ }^{39}$ Ibid. p. 54.

${ }^{40}$ A, Barcelona: José J. de Olañeta, 1978, p. 75.

${ }^{41}$ Ibid., p. 183.
} 
ir? ¿Queremos atravesar el mar? ¿Adónde nos arrastra esa pasión potente que a toda pasión se sobrepone? [...] Se dirá algún día de nosotros que navegando siempre hacia el Oeste esperamos llegar a unas Indias desconocidas, pero que nuestro destino era naufragar en lo infinito $\rangle^{42}$.

La crítica radical a los valores en Aurora y Humano, demasiado humano, inaugura en La ciencia feliz un nuevo destino del alma. Después de descubrir la esencia hermenéutica del ser humano, su poder creador que emerge desde un mar de fuerzas interpretantes, aparece un ser humano sin gratificación, sin castigo, sin vigilancia y sin perdón ${ }^{43}$, un ser que como piensa Imre Kertész, no tiene más un Dios al cual rendirle cuentas, un ser, en todos los sentidos, sin fundamento; Dios es lo creado y el hombre propiamente lo creador. Aquel mar de fuerzas interpretantes desde el cual el hombre despliega la vida carece del todo de fundamento, causa, principio y fin. Y en general, no existe ningún principio de finalidad, causa, orden, sentido que presida la interpretación: Dios ha muerto. «¿A dónde ha ido Dios?, ¡yo os lo voy a decir! ¡Nosotros lo hemos matado...! ¿Pero cómo hemos hecho esto? ¿Cómo fuimos capaces de vaciar el mar? ¿Quién nos dio la esponja para borrar todo el horizonte? ¿qué hicimos cuando desencadenamos esta tierra de su sol? ¿Hacia dónde se mueve ahora? ¿Hacia dónde nos movemos nosotros?... ¿No caemos continuamente?... ¿Hay un arriba y un abajo? ¿No erramos como a través de una nada infinita? ¿No nos sofoca el espacio vacío?... ¿No llega continuamente la noche y más noche? ¿No habrán de ser encendidas las lámparas al mediodía?... ¡Dios ha muerto!... ¡Y nosotros lo hemos matado!... ¿No es la grandeza de este hecho demasiado grande para nosotros? ¿No hemos de convertirnos nosotros mismos en dioses, sólo para hacer dignos ante ellos? ¡Nunca hubo hecho más grande - y quienquiera nazca después de nosotros, pertenece por la voluntad de este hecho a una historia más alta que todas las habidas hasta ahora! $\rangle^{44}$

La existencia es infinita profundidad o abismo porque está asentada en el devenir de una pluralidad de instintos, esto es, en la vida y no en Dios o en un supuesto dador de estabilidad y permanencia. El orden de lo simbólico descansa sobre un plenum que deviene infinitamente, esta pluralidad de instintos, a veces en contradicción, otras veces en armonía, torna la existencia problemática, pues carece de un criterio de verdad o de valor previo sobre el cual simbolizar. Lo más propio de la existencia humana, es decir, su poder de simbolización, se sostiene sobre el abismo, sobre el propio devenir carente de ley o principio o

${ }^{42}$ A p. 206.

${ }^{43}$ «¿No tendremos nunca el derecho de estar solos con nosotros mismos? ¿Nunca más sin andaderas, custodias, sin andaderas, sin dones? Si hay siempre otro cerca de nosotros, lo mejor del coraje y de la bondad del mundo se vuelve imposible. ¿No desearíamos entonces entregarnos enteramente al diablo, contra esta invasión del cielo? Pero ya no es necesario; aún más, sólo ha sido un sueño. ¡Despertemos!» A p. 174.

${ }^{44} \mathrm{GC}$ p. 115. 
thelos. Nietzsche descubrió que el ser humano se encuentra inmerso en el lenguaje, que el lenguaje es expresión de fuerzas e instintos, que los absolutos que la razón busca y los ideales se gestan desde el seno mismo de la vida y que por lo tanto, los valores cognoscitivos y morales no responden a un fin supremo de la razón o del ser humano. Es aquí donde Nietzsche reclama un nuevo talante para el ser humano consciente del abismo, la aptitud para vivir en la apariencia con todos sus velos, la aptitud para crear ficciones que permitan vivir. Inventar para vivir, vivir para inventar. Esa concepción despierta un nuevo arte de vivir: soñar sabiendo que se sueña. «Desperté a la conciencia de [...] que precisamente soñaba y de que tenía que continuar soñando, para no perecer: así como el sonámbulo tiene que continuar soñando para no despeñarse $\rangle^{45}$. Ante semejante inauguración del alma sin sentido y ante la presencia del más inquietante de los huéspedes como llama Nietzsche al nihilismo, el filósofo está urgido de inventar un sentido inaudito hasta ahora: el sentido de la tierra (der Sinn der Erde), hasta hoy imposible de concebir porque el ser humano sólo aprendió proyectar más allá de la tierra y de sí sus deseos, sus anhelos y esperanzas.

En Así habló Zaratustra, la desestructuración de la razón hace aparecer al mundo como un Abismo de luz (Licht Abgrund); entonces las oposiciones, las jerarquías desaparecen, y todo cuanto hay en la Tierra se vuelve literalmente visible: «todas las cosas están bautizadas en el manantial de la eternidad y más allá del bien y del mal, el bien y el mal mismos no son más que sombras intermedias y nubes pasajeras $\rangle^{46}$. Nietzsche en su descenso al abismo inaugura una subjetividad entendida como voluntad de ocaso o como fuerza de superación de sí, esto es, como voluntad de devenir. En este constante ser tránsito y ocaso, no puede haber, ni se puede querer un fundamento estable en el hombre. Acepta un ir haciéndose-deshaciéndose, conociendo-desconociéndose: el ser humano para ser tránsito, tiene que ser ocaso. El individuo como voluntad de ocaso, congruente con la vida y su permanente constitución, está en condiciones de abrir el abismo del hombre, de quitar el suelo definitivo que existía bajo sus pies, Dios. De esta manera, desaparecen las estructuras que solidificaban la existencia. Al abandonar la pretensión de un fundamento último (tal es el lugar de la muerte de Dios en su obra), el ser humano descubre su auténtico poder: el poder aceptar la existencia tal y como es y ha sido, con todos sus instantes. Tal es el contenido de la experiencia del eterno retorno, el pensamiento más abismal. Nietzsche en su Zaratustra nos vuelve a demostrar que no hay descenso sin ascenso. Los románticos permanecieron resguardados en el abismo y el eremita que regresa al mundo de los hombres, Zaratustra, está necesitado de convertir al mundo en un abismo pero de luz, de aliar la risa y la sabiduría, paso hasta entonces imposible para el Romanticismo. Sólo Nietzsche extrajo

${ }^{45}$ Ibid., p. 63.

${ }^{46}$ Za p. 180. 
oro de las profundidades e hizo del pensamiento más abismal el más afirmativo de todos.

El abismo es condición del pensamiento más afirmativo. Desde entonces el abismo se revelará como lo propiamente posibilitante y liberador. La reflexión sobre el problema del abismo constituye todo un acontecer de sentido vivo hasta el día de hoy. Heidegger pensará que el hombre es un fundamento sin fundamento y Gadamer no aceptará elevarse desde el abismo sin fondo hasta un fundamento, su tentativa consistirá de acuerdo con Heidegger en mantenerse en el abismo, en aceptar nuestro fundamento sin fundamento, en aceptar que la facticidad del estar ahí «no es susceptible ni de fundamentación ni de deducción $\rangle^{47}$. Pero precisamente es nuestra facticidad atravesada por nuestra irrebasable e irreferente finitud, la que se convertirá en el suelo mismo de la posibilidad propia, de la anticipación de sentido y de las nuevas comprensiones: «la finitud histórica del estar ahí tan originaria y esencialmente como su estar proyectado hacia posibilidades futuras de sí mismo» ${ }^{48}$. Tanto en Nietzsche, Heidegger y Gadamer el abismo será un fundamento infundado de las posibilidades propias y liberadoras del ser humano y de su poder transfigurador y creador. Podemos decir, que después de Kant una línea del pensamiento replanteará las tareas de la metafísica en términos de una desfundamentación reflexiva de las aspiraciones de la razón hacia lo incondicionado, y en este sentido en una profundización del abismo, en su replanteamiento y en un conocimiento de lo que permite y abre en el ser humano.

${ }^{47}$ Gadamer, Hans-Georg, Verdad y método I, Salamanca: Sígueme, 1975, p. 319.

${ }^{48}$ Ibid., p. 328. 